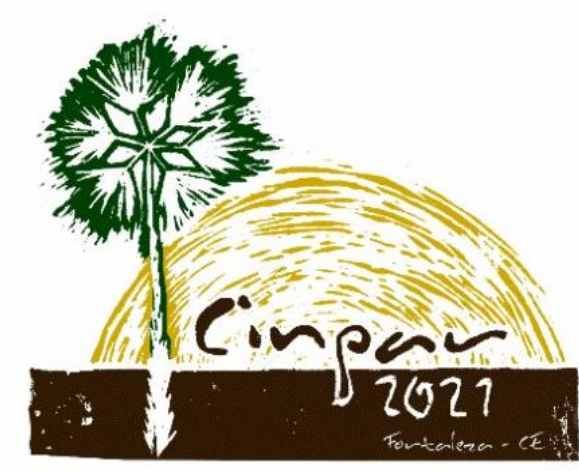

XVII Congresso Internacional sobre Patologia e

Reabilitação das Construções

XVII Congreso Internacional sobre Patología y Rehabilitación de las Construcciones

XVII International Conference on Pathology and Constructions Rehabilitation

FORTALEZA (Brasil), 3 a 5 de junho de 2021

https://doi.org/10.4322/CINPAR.2021.020

\title{
Degradação nos elementos estruturais de Obras de Arte Especiais devido à ação biológica em rodovias federais na região Norte e Nordeste do Brasil
}

\section{Degradation in the structural elements of bridges and viaducts due to biological action on federal highways in Northern and Northeast Brazil}

\author{
Rodrigo Pereira ${ }^{1}$, Caroline P. Alves ${ }^{2}$, Pedro H. Lucena ${ }^{3}$, Ana C. V. Salles ${ }^{4}$, Giovana A. de Oliveira ${ }^{5}$ \\ ${ }^{1}$ PUC-MG, Belo Horizonte, Brasil, rodrigoestruturas@gmail.com \\ 2 UFMG, Belo Horizonte, Brasil, caroline.pedrosaalves@gmail.com \\ ${ }^{3}$ UFMG, Belo Horizonte, Brasil, pedrohenri_que@outlook.com \\ ${ }^{4}$ UFMG, Belo Horizonte, Brasil, anasalles1304@gmail.com \\ ${ }^{5}$ UFMG, Belo Horizonte, Brasil, abreu_giovana@hotmail.com
}

\begin{abstract}
Resumo: Os morcegos são mamíferos presentes em todas as regiões do Brasil, sendo seu habitat alterado devido a desmatamentos e queimadas. Desta maneira, as Obras de Arte Especiais (OAEs), estão se tornando um local de moradia para esses animais. As OAEs, como pontes e viadutos, são constituídas de elementos fabricados para suportar cargas considerando os tipos de veículos que trafegarão na via, meio ambiente e sua funcionalidade. Para tanto, não são projetadas para serem abrigos para mamíferos, sendo esse fator preponderante para a degradação de seus materiais de construção. Os ácidos componentes da excreção final do morcego fazem com que o concreto e elementos metálicos alterem suas caraterísticas físicas, não atingindo sua vida útil conforme normas vigentes. Ainda assim, essas instruções não indicam nenhum tipo de proteção a esses elementos contra esses tipos de dano. No referido trabalho, serão apresentadas as principais manifestações patológicas em Obras de Arte Especiais e as indicações de seus determinantes, como excremento de morcego, fator causador da degradação nos elementos de concreto e elementos metálicos. Além disso, será apresentado um estudo de nove pontes nas regiões norte e nordeste do Brasil, exemplificando o contexto abordado.
\end{abstract}

Palavras-chave: Obras de Arte Especiais; Degradação biológica; Concreto; Manifestações Patológicas.

Abstract: Bats are mammals present in all regions of Brazil, with their habitat altered due to deforestation and fires. In this way, bridges and viaducts are becoming a place where these animals live. These structures are made up of elements manufactured to support loads considering the types of vehicles, the environment and their functionality. Therefore, they are not designed to be shelters for mammals, these factors being preponderant for the appearance of defects in their construction materials. Acids present in the final bat excretion, causes concrete and metallic elements to change their physical characteristics, not reaching their useful life according to current regulations. Even so, these instructions do not indicate any type of protection for these elements against this damage. In the referred work, the main pathological manifestations in bridges and viaducts and the indications of their determinants, such as bat excrement, will be shown to cause degradation in concrete and metallic elements. In addition, a study of nine bridges in the north and northeast regions of Brazil will be presented.

Keywords: Bridges and viaducts, biologic degradation, concrete, pathology.

\section{Introdução}


Segundo a American Association of State Highway and Transportation Officials (AASHTO, 2017), vida útil de projeto de fadiga representa o número de anos que uma estrutura deve resistir às cargas de tráfego adotadas sem fadigar e especifica esse valor como 75 anos. Para que esse tempo seja alcançado, as manutenções devem ser realizadas em tempo hábil, agindo de forma breve nos problemas identificados em uma estrutura, de forma a reduzir os custos das intervenções.

Muitos fenômenos podem prejudicar a integridade do concreto, dentre eles: falhas de projeto, como baixa resistência ou traço inadequado à agressividade do meio; erros de execução, como brocas e nichos de concretagem; ou ainda problemas após a conclusão da obra. Dentro deste último estão os impactos físicos, a infiltração de águas, a agressão por fogo e um fenômeno menos conhecido: a degradação por ação biológica, tema deste trabalho. A expressão degradação biológica no contexto deste artigo trata especificamente do efeito nocivo do contato do guano (acúmulo de excrementos) de morcegos com a estrutura de concreto.

No país existem 167 espécies de morcegos que ocorrem em todo o território nacional, Amazônia, Cerrado, Pantanal, Mata Atlântica, nordeste, pampas gaúchos e áreas urbanas. São animais noturnos e todas as famílias brasileiras utilizam a ecolocalização para se orientar, apesar de não serem cegos, existindo alguns frugívoros maiores que, além da ecolocalização, utilizam a visão para se localizarem (REIS et al., 2007).

Por seus hábitos noturnos, esses animais estão relativamente protegidos da extinção. No entanto, estão cada vez mais próximos aos seres humanos dado que seus habitats naturais vêm sendo destruídos devido ao crescente desmatamento no Brasil. De 2019 para 2020 o monitoramento por satélite do desmatamento por corte raso na Amazônia Legal apontou um aumento de 9,5\% no desmatamento, com o valor mais alto desde o ano de 2008, segundo o Instituto Nacional de Pesquisas Espaciais - INPE (2020). No caso das queimadas, o ano de 2020 apresentou um aumento de mais de $12 \%$ no número de focos ativos detectados por satélite em relação ao ano anterior, sendo o maior número desde o ano de 2010 (INPE, 2021).

Além disso, a interferência das ações humanas por meio de construções modifica o ambiente de diversas formas. Na Figura 1 abaixo, está apresentada um exemplo de alteração de rota dos morcegos devido à construção de uma rodovia no traçado da rota original. Segundo o National Roads Authority (2005) a construção de pontes e viadutos oferece aos morcegos uma opção segura para cruzar a rodovia implantada, com isso, essas estruturas passam a fazer parte da nova rota. Combinando esse fator ao desmatamento crescente, a presença de morcegos em Obras de Arte Especiais (OAEs) em algumas regiões do Brasil se tornou recorrente.

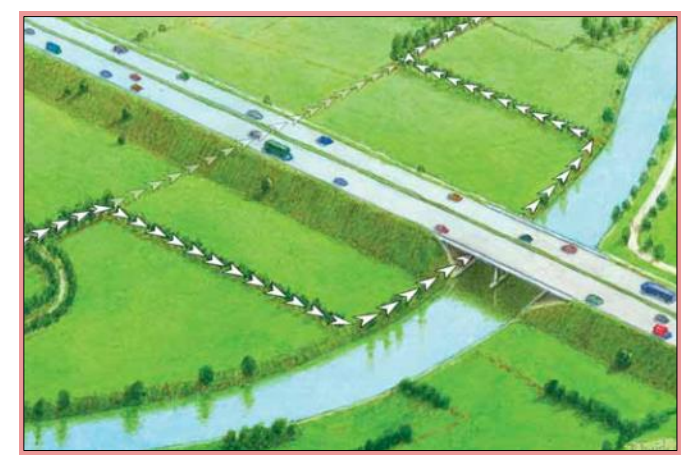

Figura 1 - Mudança de rota devido à construção de uma rodovia (National Roads Authority, 2005)

Segundo o US Department of Transportation (DOT, 2017), os morcegos costumam buscar abrigo em locais escuros, que se assemelham às condições em uma caverna, com locais propícios a se pendurarem e geralmente distantes do solo, de modo a evitar predadores. Nas OAEs, essas características podem estar presentes isoladamente ou combinadas.

Além de serem estruturas que permitem o distanciamento do solo, as emendas de concretagem entre vigas e lajes, geralmente formam um local propício ao empoleiramento desses mamíferos, além de outros pontos como a parte superior de transversinas de ligação. A depender da posição da estrutura ou de sua largura, sua parte mais central pode ter menor incidência solar, ou ainda existirem áreas escuras dentro de vigas tipo caixão ou entre encontros e taludes de aterro. 
Segundo Clark e Stokes (2017), essa habitação pode ser classificada de duas formas, o empoleiramento diurno e o noturno. No primeiro caso, os morcegos dormem e cuidam de seus filhotes, que são deixados para trás na hora da caça, com isso, esses locais de habitação diurna costumam ser muito seguros, já no segundo caso, esses locais costumam servir apenas de abrigo temporário entre uma caça e outra, podendo dessa forma ser uma cobertura simples (CLARK; STOKES, 2017).

As OAEs são locais propícios ao empoleiramento, temporário ou permanente desses mamíferos. Contudo, esses seres podem prejudicar a estrutura do concreto com sua presença, não por apenas se pendurar nos elementos, mas pela ação de seus excrementos acumulados, o guano.

Apesar de ser um tema pouco estudado, a degradação no concreto nos elementos estruturais das obras de arte especiais devido aos excrementos dos morcegos, necessita ser incorporado e considerado junto aos estudos das normas vigentes. Como exemplo, a NBR 6118 (ABNT, 2014) indica no seu Item 6.4 "Agressividade do Ambiente" as classes de agressividade ambiental a serem consideradas nos cálculos, considerando as ações físicas e químicas que atuam sobre as estruturas de concreto, independentemente das ações mecânicas previstas no dimensionamento das estruturas.

Recomenda-se que a norma vigente deva incorporar o guano como agente químico de agressividade forte ou muito forte, a depender de seu ano de construção e seu trem tipo, classe 24, 36 ou 45.

\section{Manifestações Patológicas}

A ação danosa do guano se categoriza como biodegradação, esta pode ser classificada em três tipos: estética, física e química. Brandão e Pinheiro (1999) destacam que a maioria dos processos físicos e químicos pode reduzir a vida útil de uma estrutura em concreto, sendo dois fatores predominantes: o transporte por meio de poros e de fissuras e a presença de água. Segundo Siedel et al. (2008) os excrementos de morcegos, quando em contato com a água, formam diversos sais que são responsáveis por causar danos ao concreto.

A degradação química ocorre pela composição desses excrementos, segundo Ferreira e Martins (1999), o guano fresco tem caráter básico, úmido e com um grande valor de matéria orgânica, e com o passar do tempo torna-se ácido e seco. Segundo Malagon (2004, apud STEIGER, 2015) através de processos naturais de oxidação e decomposição, os excrementos de morcego acumulados formam vários compostos, entre eles ácidos nítrico $\left(\mathrm{HNO}_{3}\right)$, sulfúrico $\left(\mathrm{H}_{2} \mathrm{SO}_{4}\right)$ e fosfórico $\left(\mathrm{H}_{3} \mathrm{PO}_{4}\right)$, que conferem ao guano um $\mathrm{pH}$ ácido, que varia entre 4,3 a 5,5.

A simples existência de guano nas Obras de Artes Especiais não é preocupante em curto prazo. A manutenção regular é capaz de remover o acúmulo de excrementos de morcegos antes que se torne ácido e afete a estrutura. No entanto, muitas vezes as OAEs passam por longos períodos sem intervenções, dessa forma manifestações patológicas podem surgir da reação do guano com os compostos do concreto.

Algumas manifestações patológicas que podem decorrer da presença desses excrementos são a infiltração no concreto, a desagregação, fissuras e desplacamentos de concreto. A corrosão das armaduras também pode ocorrer em resultado da diminuição do $\mathrm{pH}$ do concreto.

A água juntamente com os compostos presentes no guano, é capaz de penetrar nos vazios do concreto, por seus poros, afetando diretamente suas características estruturais, podendo chegar até as armaduras presentes nos elementos da Obra de Arte Especial. A maior porosidade da pasta de cimento favorece a penetração de soluções agressivas, que intensificam o ataque dado que estas passam a agir no interior da massa (BRANDÃO; PINHEIRO, 1999).

Segundo Cwalina (2008), a hidratação do cimento resulta em hidróxido de cálcio $\left(\mathrm{Ca}(\mathrm{OH})_{2}\right)$, que reage com o dióxido de carbono $\mathrm{CO}_{2}$, presente no ar resultando em carbonato de cálcio $\left(\mathrm{CaCO}_{3}\right)$. Ambos, hidróxido e carbonato de cálcio, reagem com diferentes substâncias, principalmente os ácidos e ainda alguns sais, aqui provenientes do guano. Os produtos dessas reações são sais expansivos no interior do concreto, que provocam sua fissuração de dentro para fora (CWALINA, 2008). O processo de fissuração pode levar ao desplacamento de concreto e esses danos aceleram a deterioração, uma vez que expõem ainda mais o concreto e sua armadura. 


\section{Definições normativas}

A NBR 6118 (ABNT, 2014) apresenta classes de agressividade ambiental, que categoriza a agressividade do meio em fraca, moderada, forte ou muito forte e varia com a exposição da estrutura e suas partes. Essa classificação é responsável pela determinação de espessura de cobrimento de armadura, teor máximo de íons cloreto para proteção das armaduras do concreto, classe do concreto e ainda pela relação água cimento, definidos na NBR 12655 (ABNT, 2015) e apresentados também na NBR 6118 (ABNT, 2014).

Segundo Brandão e Pinheiro (1999), fatores como relação água/cimento; quantidade, composição e finura do cimento; quantidade, forma e dimensões dos agregados; grau de hidratação do cimento; aderência entre a pasta e o agregado; presença e quantidade de adições e de aditivos; qualidade da execução e outros afetam a porosidade do concreto e, consequentemente, na sua permeabilidade e capacidade de absorção de água, dessa forma, na sua resistência ao ataque químico.

A determinação desses fatores em normas nacionais tem, então, o objetivo de minimizar os impactos dos agentes agressivos ao concreto e, consequentemente, ao aço, garantindo dessa forma uma maior durabilidade aos materiais. A maior parte dessas recomendações visa diminuir a porosidade, que é responsável, juntamente com a presença de água, pela diminuição da vida útil do concreto por processos físicos e químicos, como dito anteriormente.

\section{Estudo de Caso}

Neste trabalho, foram analisadas nove pontes nas regiões Norte e Nordeste do Brasil, sendo uma no estado do Amapá, duas no estado do Pará, três no estado do Tocantins e duas no Rio Grande do Norte. As pontes passaram por inspeção visual e por meio desta foi observada a presença de morcegos ou apenas de seus excrementos. As obras têm diferentes tipos de estrutura, selecionadas desta maneira de modo a apresentar danos causados pela ação biológica de forma mais ampla, identificando elementos e danos diferentes.

Buscou-se apresentar diferentes elementos das OAEs utilizados para o empoleiramento. Na Figura 2a a seguir é possível observar que os morcegos se posicionam na junção de concretagem entre viga e laje e também nas juntas da pré-laje. Já na Figura $2 \mathrm{~b}$ os mamíferos podem ser observados na parte posterior de um encontro.

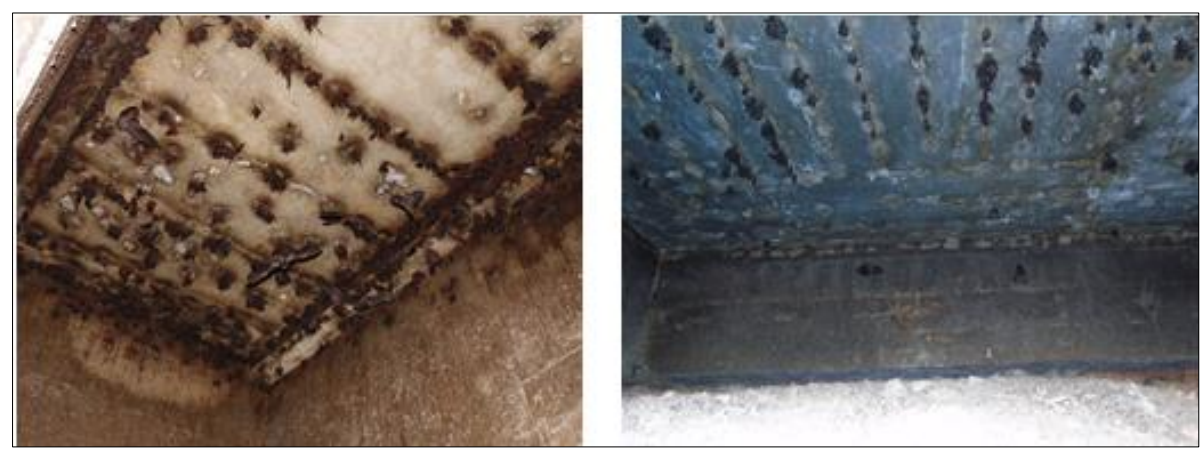

Figura 2 - (a) Morcegos empoleirados em laje e viga na Ponte sobre o Igarapé Majuba, no km 175,1 da BR-230, no Pará; (b) Morcegos empoleirados em parte posterior de encontro na Ponte sobre o Rio do Ouro, no km 479,8 da BR-153, no Tocantins

Além das alterações de pH já mencionadas, que ocorrem com o tempo nos depósitos de excrementos, a coloração das manchas de guano normalmente se apresenta mais escura, próxima ao marrom, no guano fresco e mais próxima do cinza ou branco no guano mais antigo. Essas diferenças podem ser observadas nas figuras a seguir. A figura 3a apresenta um depósito recente, com manchas escuras próximas às quinas entre as vigas e as transversinas de ligação. Já a figura $3 \mathrm{~b}$ apresenta manchas claras nas frestas entre as pré-lajes e nos encontros entre vigas e laje.

Em ambas figuras não foram observados morcegos no momento da inspeção, durante o dia. Pode-se considerar que na primeira imagem o local sirva apenas como abrigo noturno, aquele no qual os morcegos se empoleiram entre uma caçada e outra, temporariamente, para descansar e se proteger de predadores. 
No caso da figura 3b, é mais provável que esse local tenha sido abandonado pela colônia que ali habitava, uma vez que há apenas manchas antigas de guano.

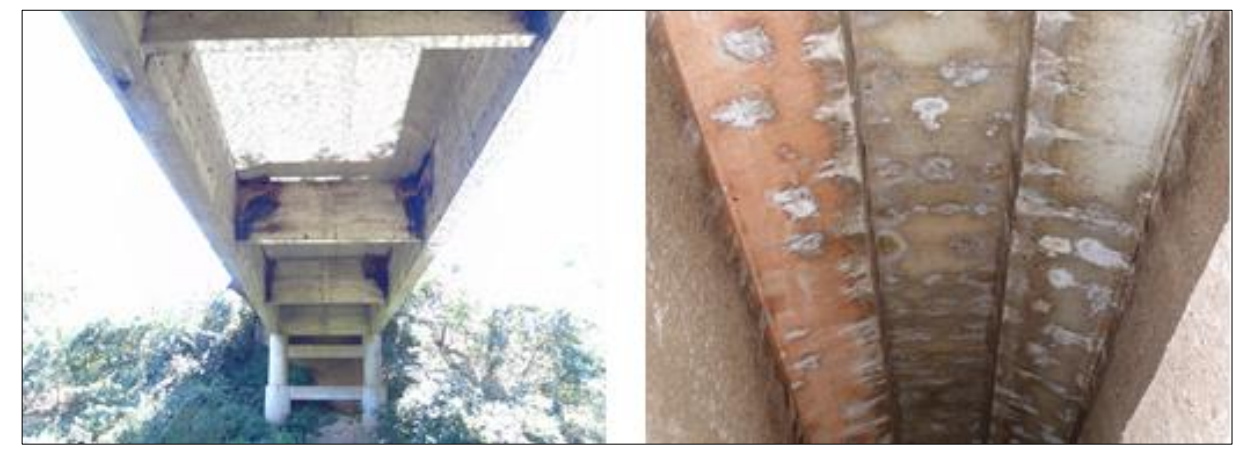

Figura 3 - (a) Manchas de guano na Ponte sobre o Rio São Martinho, no km 100,2 da BR-230, no Tocantins;

(b) Manchas de guano na Ponte sobre o Igarapé Loirinho, no km 234,3 da BR-155, no Pará

É interessante destacar que todos os tipos de estruturas estão sujeitas à ação nociva da habitação dos morcegos, inclusive em OAEs recentes, como a da Ponte sobre o Igarapé Loirinho, apresentada na Figura 3b que apresenta uma estrutura em concreto protendido.

O tamanho das colônias de morcegos também varia de uma OAE para outra. Nas figuras $4 a$ e $4 \mathrm{~b}$ a seguir é possível observar uma colônia menor e uma maior respectivamente.

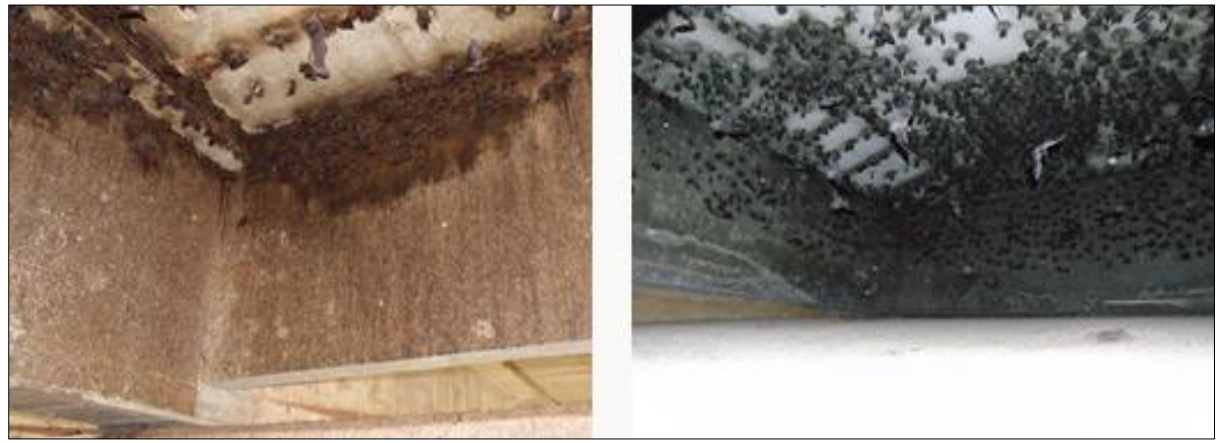

Figura 4 - (a) Colônia de pequeno porte na Ponte sobre o Igarapé Majuba, no km 175,1 da BR-230, no Pará;

(b) Colônia de grande porte na Ponte sobre o Córrego Bocodó, no km 12,7 da BR-153, no Tocantins

A depender do tamanho da colônia e do tempo de habitação da mesma em uma estrutura, a quantidade de guano pode ser enorme. Na Ponte sobre o Igarapé do Quatorze é possível observar o acúmulo dos excrementos no talude de aterro da estrutura, com formações parecidas com estalagmites (Figura 5).
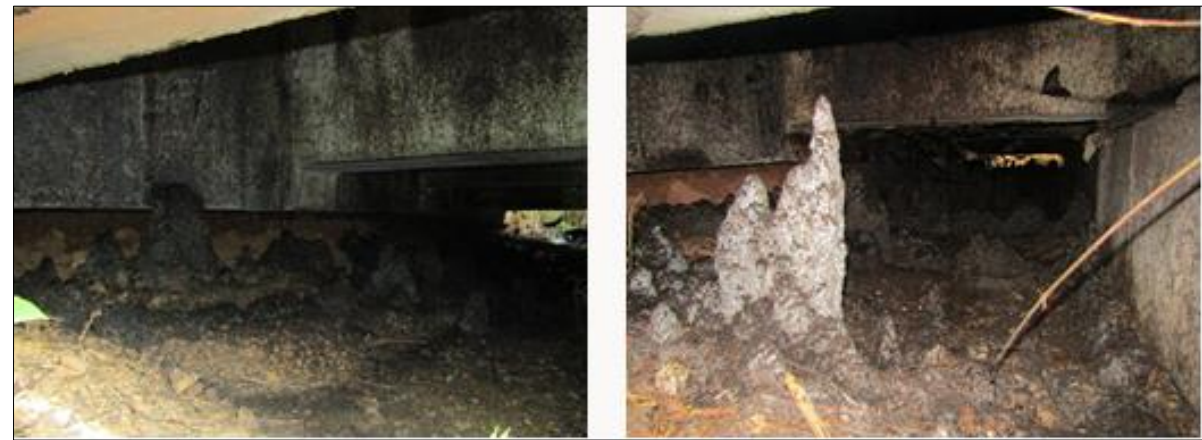

Figura 5 - Acúmulo de excrementos sob a Ponte sobre o Igarapé do Quatorze, no km 808,0 da BR-156, no Amapá

Os danos também variam de estrutura para estrutura e, em alguns casos, de elemento para elemento em uma mesma OAE. A simples presença das manchas de excrementos não implica em danos ao concreto, como pode ser observado na figura $6 a$. Já na figura 6 b é possível notar infiltração, lixiviação e armadura exposta na laje da estrutura. 


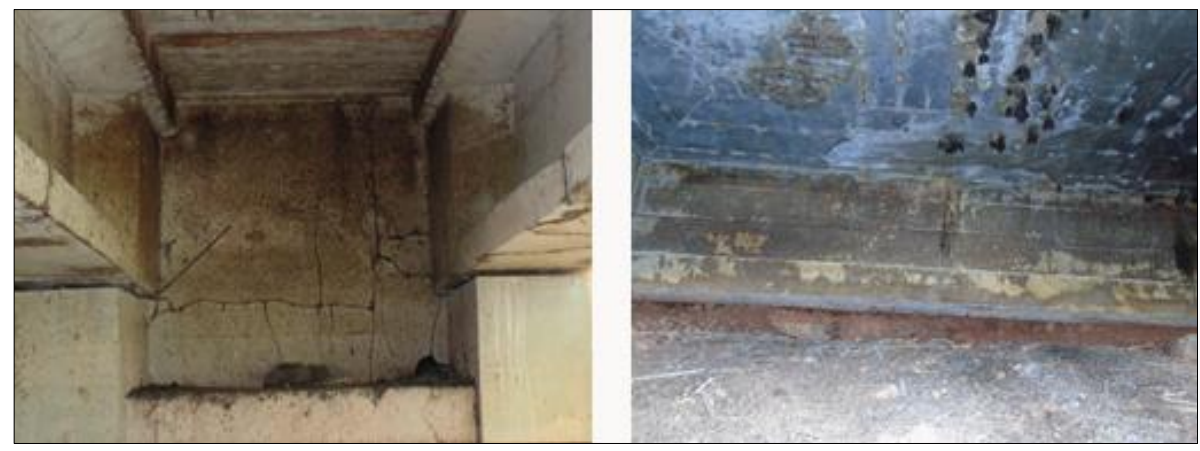

Figura 6 - (a) Presença de guano na Ponte sobre o Igarapé Loirinho, no km 234,3 da BR-155, no Pará;

(b) Manifestações patológicas na Ponte sobre o Rio do Ouro, no km 479,8 da BR-153, no Tocantins

Nas pontes sobre o Rio Bom Jesus (Figura 7) e sobre o Riacho Chapada (Figura 8) no Rio Grande do Norte, pode-se observar uma situação mais crítica dos danos. Nessas pontes é possível notar a existência de guano fresco, além do guano antigo nas áreas mais afetadas, o que evidencia que a presença dos morcegos ainda ocorre na estrutura.
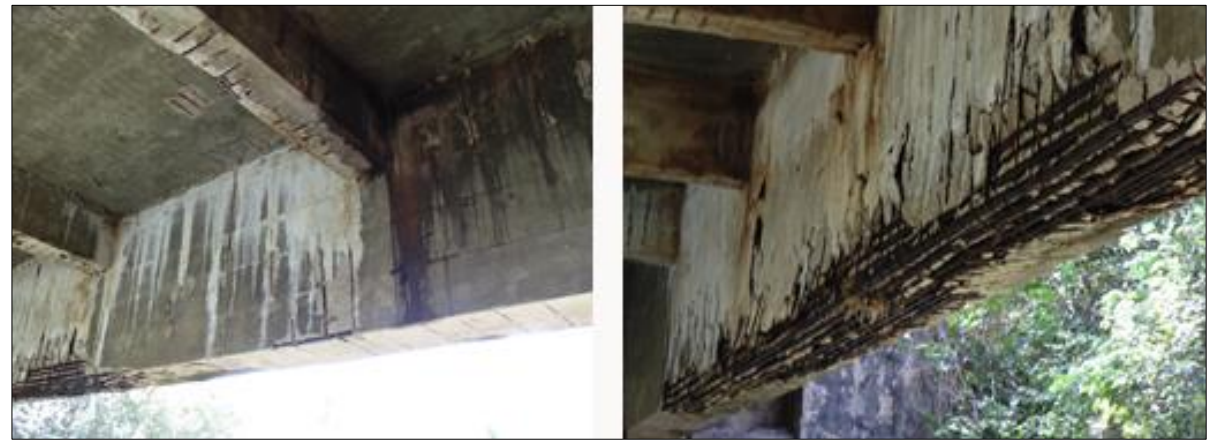

Figura 7 - Situação crítica da viga na Ponte sobre o Rio Bom Jesus, no km 46,9 da BR-226, no Rio Grande do Norte

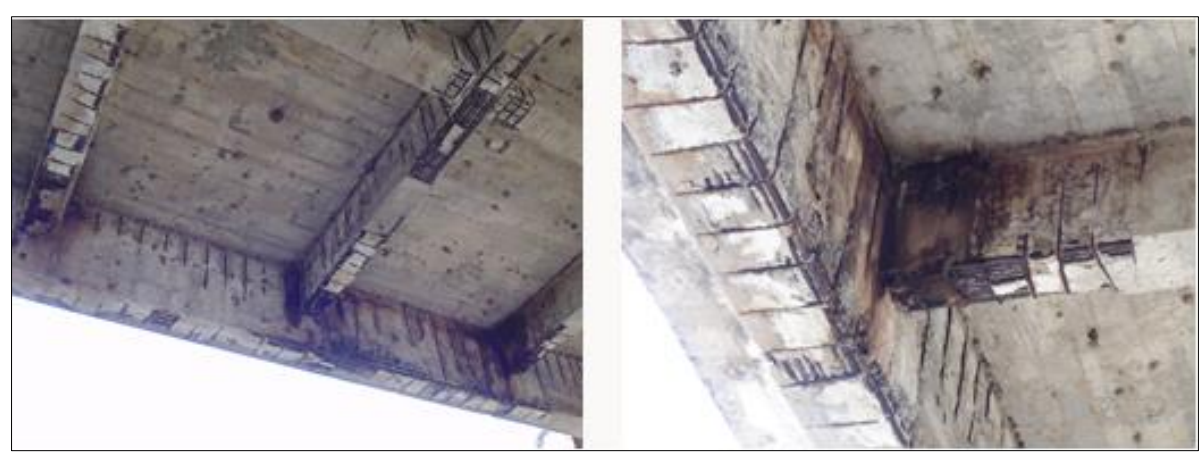

Figura 8 - Situação crítica da viga na Ponte sobre o Riacho Chapada, no km 92,2 da BR-226, no Rio Grande do Norte

É importante frisar que em OAEs em situação crítica de exposição das armaduras como as Pontes apresentadas do Rio Grande do Norte a presença de guano é relevante, uma vez que o processo de corrosão é mais acelerado que aquele que ocorre apenas com a presença de água, dado que trata-se de uma substância ácida em contato direto com as armaduras.

\section{Remoção dos morcegos}

Segundo Reis et al. (2007), as formas insetívoras dos morcegos são capazes de consumir toneladas de insetos a cada noite, as nectarívoras polinizam inúmeras espécies de plantas florestais, que desapareceriam sem sua movimentação, e as frugívoras disseminam sementes tanto pelo seu abandono após o consumo da polpa quanto por suas fezes. Para além da importância nas teias alimentares e no balanceamento dos ecossistemas nos quais estão inseridos, os morcegos são também importantes para a agricultura pelo controle de insetos e pela polinização. 
A preservação das colônias de morcegos, assim como a preservação de qualquer espécie, é necessária e digna. Ademais, pode ser conveniente manter essas colônias próximas aos seus locais de origem ou de áreas de cultivo, minimizando dessa forma os impactos que levaram essas colônias a ocuparem as OAEs. Dessa forma, algumas soluções podem ser adotadas de maneira a preservar as estruturas de concreto e também proporcionar a habitação seguro desses seres.

Em Obras de Arte Especiais com a ocorrência de morcegos, a manutenção periódica deve ocorrer em intervalos menores que os convencionais, sugere-se aqui um prazo de seis meses entre inspeções, visto que os danos provenientes do guano são de rápida ocorrência. Além disso, as manutenções devem incluir a remoção do acúmulo de excrementos de todos os elementos em que o mesmo aparecer. É importante remover completamente esse material para impedir a penetração de sais e ácidos por soluções aquosas, como apresentado anteriormente. Segundo Clark e Stokes (2017), com a correta acomodação e programação, as colônias de morcegos podem ser alocadas próximas às pontes de forma segura, durante 0 processo de manutenção.

Em Marana, no estado do Arizona nos Estados Unidos da América, foram instaladas "caixas de morcegos" na Ponte Ina Road com o objetivo de acolher os milhares de mamíferos que ali se empoleram (MENDOZA, 2018). Após passar por uma reforma, esses abrigos foram instalados de modo a permitir a habitação desses seres sem que causem prejuízos à estrutura. Mendoza explica que as caixas são recobertas por uma camada espessa de concreto e no fundo existem fendas que permitem os morcegos se pendurarem com mais facilidade, cada uma delas é capaz de comportar de 500 a 1.000 animais por abertura.

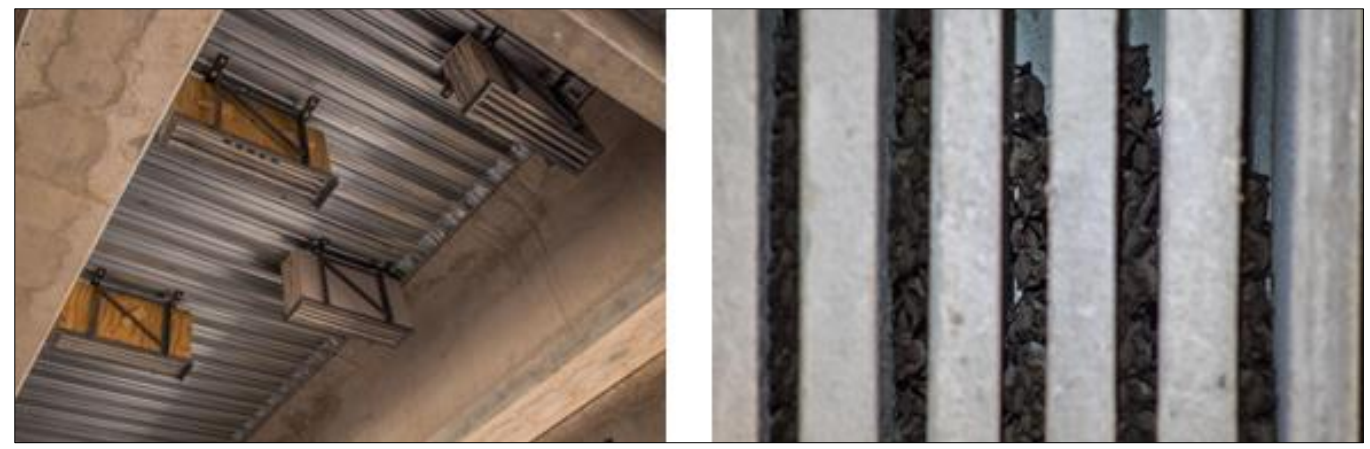

Figura 9 - Caixas de morcegos na Ponte Ina Road em Marana, Arizona (MENDOZA, 2018)

No entanto, pode-se desejar remover completamente esses seres das OAEs. A exclusão de morcegos se trata da retirada segura desses mamíferos das construções sem que haja o retorno dos mesmos, ela é feita com a utilização de materiais como alumínios reflexivos, que permitem a saída desses animais e posteriormente os vãos habitáveis são preenchidos com materiais diversos para evitar seu regresso (CLARK; STOKES, 2017).

\section{Conclusões}

Mostrou-se que, além do desmatamento e das queimadas, a implantação de Obras de Arte Especiais pode interferir na rota e impactar os hábitos de morcegos em localidades diversas. A ocorrência desses mamíferos em OAEs pode ser muito danosa à estrutura, com a corrosão química do concreto e, em alguns casos, das armaduras. Isso se dá devido à acidez do guano, adquirida com o passar do tempo, e sua capacidade de, juntamente com a água, penetrar sais e ácidos no concreto. Considerando-se a evolução das construções de infraestrutura, como a construção de rodovias, os habitats dos morcegos foram alterados. Como pode-se observar, várias OAEs se tornaram suas moradias, sendo os elementos da superestrutura como viga, transversina e laje como seus principais poleiros. Os danos ocorrem em diferentes locais, com maior ou menor incidência, a variar com o tipo de habitação do local. Apresentou-se formas de estender a durabilidade do concreto, aumentando sua capacidade de resistência a ataques químicos, incluindo àqueles devido à ação biológica. Ressaltou-se a importância das manutenções periódicas nas Obras de Artes Especiais para alcançar a vida útil desejada, com a remoção do acúmulo de guano dos elementos. Nove pontes nos estados do Amapá, Pará, Tocantins e Rio Grande do Norte nas regiões Norte e Nordeste do Brasil, foram analisadas e a presença de morcegos era sistematicamente observada. Como estudo de caso apresentou-se fotos de guanos frescos e secos, diferentes elementos, etapas de deterioração e tamanhos de colônias. Destacou-se 
que mesmo com a recorrente presença desses mamíferos nas OAEs e os danos provenientes de sua habitação, este tema ainda é pouco abordado na literatura nacional. Por isso, este estudo objetiva ser um parâmetro nacional nas buscas sobre o assunto. Destacou-se a importância das colônias de morcegos para os ecossistemas nos quais estão inseridos e também para a agricultura. Por isso a importância de se preservar a habitação segura desses seres. Por fim foi exposto o exemplo de uma solução alternativa para abrigar esses seres sob as OAEs sem que haja prejuízos para a estrutura.

\section{Referências Bibliográficas}

AASHTO - American Association of State Highway and Transportation Officials. (2017). LRFD Bridge design specifications. Washington: AASHTO, 2017.

Associação Brasileira De Normas Técnicas. (2015). ABNT NBR 12655: Concreto de cimento Portland - Preparo, controle, recebimento e aceitação. Rio de Janeiro: ABNT, 2015.

Associação Brasileira De Normas Técnicas. (2014). ABNT NBR 6118: Projeto de estruturas de concreto Procedimento. Rio de Janeiro: ABNT, 2014.

Brandão, A. M. S., Pinheiro, L. M. (1999). Qualidade e Durabilidade das Estruturas de Concreto Armado: Aspectos Relativos ao projeto. USP São Carlos: USP São Carlos, 1999. (Cadernos de Engenharia de Estruturas, Número 8).

Clark, K.; Stokes, D. (2017). Bats in Bridges: How to complete your Project and protect these Champion bug zappers. [S. I.], 29 out. 2017. Disponível em: https://www.constructormagazine.com/bats-in-bridges-2/. Acesso em 30 dez. 2020.

Cwalina, B. (2008). Biodeterioration Of Concrete. Architecture Civil Engineering Environment ACEE, Gliwice, v. 1, n. 4, p. 133-140, 2008.

Federal Transportation Agency - Us Department of Transportation - DOT. (2017). Preliminary Bat Assessment Guidelines for Bridges/Structures. APPENDIX D: Bridge/Structure Assessment Guidance. Indiana, maio 2017.

Ferreira, R.L.; Martins, R.P. (1999) Guano de morcegos: fonte de vida em cavernas. Ciência Hoje, São Paulo, v. 25, n. 146, p. 34-40, 1999.

Mendoza, A. (2018). Bats, boxes and bridges: Officials build new homes for bats in Marana. [S. I.], 7 mai. 2018. Disponível em: https://www.insidetucsonbusiness.com/news/bats-boxes-and-bridges-officialsbuild-new-homes-for-bats/article_ed62b478-2235-11e8-afe7-93abe2e1f338.html. Acesso em: 29 dez. 2020.

Ministério Da Ciência, Tecnologia E Inovações (Brasil). Instituto Nacional De Pesquisas Espaciais. (2021). Monitoramento dos Focos Ativos por Países: Comparação do total de focos ativos detectados pelo satélite de referência em cada mês. Brasília, 4 jan. 2021. Disponível em: http://queimadas.dgi.inpe.br/queimadas/portal-static/estatisticas_paises/. Acesso em: 4 jan. 2021.

Ministério Da Ciência, Tecnologia E Inovações (Brasil). Instituto Nacional De Pesquisas Espaciais. (2020). Monitoramento do Desmatamento da Floresta Amazônica Brasileira por Satélite. Brasília, 30 nov. 2020. Disponível em: http://www.obt.inpe.br/OBT/assuntos/programas/amazonia/prodes. Acesso em: 15 dez. 2020.

National Roads Authority (Irlanda). (2005) Best Practice Guidelines for the Conservation of Bats in the Planning of National Road Schemes. Dublin, 2005.

Reis, N. R. et al. (2007). Morcegos do Brasil. 1. ed. Londrina: [s. n.], 2007.

Siedel, H.; Leisen, E. V. P.; Leisen, H. (2008). Salt load and deterioration of sandstone at the temple of Angkor Wat, Cambodia. In: International Congress on Deterioration and Conservation of Stone, 11., 2008, Torun. [Proceedings]. Torun: [s. n.], 2008. p. 267-274.

Steiger, V. (2015). Contribuição Para o Estudo da Degradação Química da Pasta De Cimento: Simulação da Atividade Agressiva do Guano de Morcegos. 2015. 117 p. Dissertação (Mestrado em Engenharia e Tecnologia De Materiais) - Pontifícia Universidade Católica do Rio Grande do Sul, Porto Alegre, 2015. 